Criar Educação, Criciúma, v. 8, no2, ago/dez 2019.- PPGE - UNESC - ISSN 2317-2452

\title{
O ENSINO DE ARTE E A EXPERIÊNCIA: NARRATIVAS EM TORNO DO PROJETO MORRO GRANDE EM ARTE
}

Mikael Miziescki ${ }^{1}$

\author{
Aurélia Regina de Souza Honorato²
}

\section{RESUMO}

Este presente artigo se desenvolveu em torno das quatro edições do projeto "Morro Grande em Arte", executado na cidade de Morro Grande que está localizada no extremo sul de Santa Catarina. O projeto aconteceu na EMEF Prefeito Dário Crepaldi por meio das aulas de Artes, objetivando desconstruir estereótipos na escola e na comunidade e também oportunizar aos participantes vivências relacionadas às diferentes linguagens artísticas, valorizando a cultura local, contemplando a história da arte enquanto referencial teóricoprático, enaltecendo o processo criativo dos alunos na busca do refletir os múltiplos conhecimentos em arte e sobre arte. A proposta se construiu a partir das produções feitas pelos alunos nos anos letivos de 2014 à 2017, na perspectiva de serem potencializadas numa exposição coletiva que se propôs a ocupar espaços da cidade, como Salões de Festas e Centros Comunitários. Nas quatro edições, cerca de 1400 pessoas visitaram as exposições do projeto, contando com os trabalhos artísticos de mais de 200 alunos e 10 artistas convidados. Neste texto apresentamos nosso olhar para as múltiplas experiências estéticas produzidas pelo projeto "Morro Grande em Arte", compreendendo a disciplina de Artes e o aluno como produtores de conhecimento crítico-reflexivo em torno de inquietações contemporâneas individuais, coletivas e culturais, considerando os efeitos de transformação na cidade e na escola. As inquietações que aqui perpassam, dialogam com autores como Honorato (2015), Rancière (2009, 2012 e 2015), Feldhaus (2014), entre outros.

Palavras-chave: experiência; arte; educação;

\section{THE TEACHING OF ART AND THE EXPERIENCE: NARRATIVES AROUND THE MORRO GRANDE EM ARTE PROJECT}

\begin{abstract}
This article was developed around the four editions of the "Morro Grande em Arte" project, executed in the city of Morro Grande, located at the southern end of Santa Catarina. The project took place at the EMEF Prefeito Dário Crepaldi through the Arts classes, aiming to deconstruct stereotypes in school and in the community and to provide participants with experiences related to different artistic languages, valuing the local culture, contemplating the history of art as a theoretical-practical reference, extolling the creative process of the students in the search to reflect the multiple knowledge in art and on art. The proposal was built from the productions made by students in the academic years 2014 to 2017, with the
\end{abstract}

${ }^{1}$ Graduado em Artes Visuais (Licenciatura) e Pós-Graduando em Teoria e História da Arte, ambas pela Universidade do Estremo Sul Catarinense. E-mail: miziescki@gmail.com

2Doutora em Ciências da Linguagem pela Universidade do Sul de Santa Catarina e Mestre em Educação pela Universidade do Extremo Sul Catarinense. E-mail: arh@unesc.net 
Criar Educação, Criciúma, v. 8, no2, ago/dez 2019.-PPGE - UNESC - ISSN 2317-2452

prospect of being potentialized in a collective exhibition that proposed to occupy spaces of the city, such as Halls of Festivals and Community Centers. In the four editions, about 1400 people visited the project exhibitions, counting on the works of more than 200 students and 10 invited artists. In this text we present our look at the multiple aesthetic experiences produced by the "Morro Grande em Arte" project, comprising the discipline of Arts and the student as producers of critical-reflective knowledge around contemporary individual, collective and cultural concerns, considering the effects of city and school. The concerns that surround us, dialogue with authors such as Honorato (2015), Rancière (2009, 2012 and 2015), Feldhaus (2014), among others.

Keywords: experience; art; education;

\section{INTRODUÇÃO}

Em fevereiro de 2014, cheguei pela primeira vez na Escola Municipal de Ensino Fundamental Prefeito Dário Crepaldi, na comunidade de Nova Roma em Morro Grande - Santa Catarina, para lecionar a disciplina de Artes para duas turmas: $4^{\circ}$ e $6^{\circ}$ anos. Desafiei-me a entender a realidade escolar no princípio do meu trabalho naquele espaço, compreendendo que a cidade possui aproximadamente três mil habitantes e que a grande maioria trabalha com agricultura. Percebi de antemão que os alunos tinham um grande potencial artístico que era pouco explorado e que suas visões eram restritas a propagação de estereotipias visuais (desenho impresso, lembrancinha, artesanato, moldes, fôrmas, entre outros). A pesquisa que desenvolvi para conclusão do curso de Artes Visuais - Licenciatura ${ }^{3}$ da Universidade do Extremo Sul Catarinense, questionou o uso dos estereótipos na disciplina de Artes e na escola, e com base neste estudo propus com minhas turmas uma desconstrução inicial a partir da arte contemporânea e da arte moderna.

Como todo processo de desconstrução é lento, muitas dificuldades surgiram ao longo do percurso, principalmente no ato de reconhecer-se produtor de conhecimento, de valorizar sua produção como potência artística e de compreender que seu trabalho tem força para propor reflexões. Os alunos desconheciam artistas catarinenses e contemporâneos brasileiros, além das vanguardas modernas. Havia preconceito com relação ao abstrato e ridicularização com pouca valorização da

${ }^{3}$ MIZIESCKI, Mikael. Trabalho de Conclusão de Curso: (Des)construindo estereótipos: uma conversa com professoras de artes e pedagogas da região da AMESC. Criciúma: UNESC, 2015. Disponível em: http://repositorio.unesc.net/handle/1/3708 
cultura catarinense e da cidade de Morro Grande. Supervalorizavam o figurativismo realista e sofriam quando não atingiam suas expectativas perante a essa ideia de belo, impregnada em suas mentes.

Mesmo com todas as dificuldades, as produções e os conceitos foram me surpreendendo, onde percebi que eram muito inquietantes para ficar apenas restritas as paredes da escola. A partir disso surge o projeto "Morro Grande em Arte", que se constitui como um evento, desde 2014, que oportuniza espaços para o que foi produzido nas aulas de Artes durante o ano letivo em formato de exposição coletiva, aberta para o público. As quatro edições que já aconteceram, reuniram aproximadamente 700 produções e receberam mais de 1400 espectadores, nos anos de 2014, 2015, 2016 e 2017. Nessa última edição, recebemos 700 pessoas de cinco municípios diferentes ao longo dos dois dias de evento, que contou também com trabalhos de artistas convidados e objetos históricos da cidade. A exposição passeia pelas múltiplas linguagens da arte e tem como objetivo geral desconstruir estereótipos e oportunizar vivências relacionadas as diferentes linguagens artísticas, valorizando a cultura do Brasil, do estado de Santa Catarina e do município de Morro Grande, contemplando a história da arte como referencial teórico-prático, enaltecendo o processo criativo dos alunos na busca por refletir a disciplina enquanto produtora de conhecimento. O projeto é amplo e foi se modificando e adaptando-se aos espaços que a cidade possui, como associações e salões paroquiais.

A cada edição a proposta lança novos desafios e me faz perceber que é com o trabalho contínuo e persistente que vamos avançando em nossos propósitos de promover a arte como potência de mudança para os sujeitos em suas singularidades e para os sujeitos em suas coletividades. Aqui nesta escrita pretendemos contextualizar as experiências desse projeto partindo das seguintes questões: como inquietar os moradores morrograndenses com as propostas do projeto "Morro Grande em Arte" a partir de seus efeitos transformadores de realidade? Como movê-los para além da valorização da produção artística dos alunos da EMEF Prefeito Dário Crepaldi, alçando o conhecimento crítico-reflexivo? 
Criar Educação, Criciúma, v. 8, no2, ago/dez 2019.- PPGE - UNESC - ISSN 2317-2452

A partir dos relatos de participantes do projeto, essa pesquisa se desenrola a começar com outras questões que complementam essa estrutura: como entender a disciplina de Artes e a criação dos alunos, enquanto produtoras de múltiplos saberes?; quais as estratégias propostas para ampliar o repertório artístico-cultural, experienciar conceitos e entender a importância dos espaços destinados a arte na cidade de Morro Grande?; e de que forma o professor-curador 4 , desafia e estimula o seu aluno a produzir e entender a sua produção enquanto potência crítico-reflexiva?. Esse artigo possuí como objetivo geral, contextualizar as múltiplas experiências estéticas acerca do projeto "Morro Grande em Arte", compreendendo a disciplina de Artes e o aluno, enquanto produtores de conhecimento crítico-reflexivo em torno de inquietações contemporâneas individuais, coletivas e culturais, considerando os efeitos de transformação na cidade em que leva o nome da proposta e no contexto escolar da EMEF Prefeito Dário Crepaldi. Considerando os objetivos específicos: desconstruir estereótipos através da Arte Moderna e Contemporânea, evidenciando os contextos brasileiros e catarinenses; propor inquietações em torno dos espaços (possíveis e impossíveis) destinados a arte, a cultura e a memória na cidade de Morro Grande - Santa Catarina; indagar através das possibilidades e dos desafios em que o professor-curador se propõe e compartilha a ideia no âmbito escolar, ao montar uma exposição coletiva de seus alunos; refletir a valorização da disciplina de Artes e suas linguagens, na cidade de Morro Grande e no âmbito escolar da EMEF Prefeito Dário Crepaldi; analisar os relatos de participantes das edições do projeto Morro Grande em Arte; e contextuar a experiência através de autores estudiosos no âmbito artístico, filosófico e educacional, além de relacionar com as indagações dos relatos dos entrevistados.

\section{DIÁLOGO METODOLÓGICO: O PERCURSO NARRATIVO}

A pesquisa sobre arte não se restringe à formulas pré-concebidas, previamente delimitadas enquanto dogmas indiscutíveis. Ela propõe inquietações acerca de estranhamentos dos autores da pesquisa, com viés desconstrutor e

\footnotetext{
${ }^{4}$ Termo apresentado ao longo da escrita, referente as propostas metodológicas do educador de intermediar as produções de seus alunos, entendendo-as como potência artística.
} 
questionador, como a arte por si só nos propõe. Os deslocamentos apresentados e analisados à luz de um referencial teórico, se constituem produto de conhecimento analítico e exploratório, investigado a partir de um contexto que sugere um mergulho profundo na escrita, na leitura e na produção. Os valores poéticos, são tão importantes (ou mais) que os valores preconcebidos cientificamente ou quantitativamente. O questionar, responde.

[...] como qualquer atividade humana, pesquisa enquanto processo não é somente fruto do racional: o que é racional é a consciência do desejo, a vontade e a predisposição para tal, não o processo da pesquisa em sim, que intercala o racional e o intuitivo na busca comum de solucionar algo. Esses conceitos servem tanto para a ciência quanto para a arte, pois pesquisa é a vontade e a consciência de se encontrar soluções, para qualquer área do conhecimento humano (ZAMBONI, 2012, p. 51).

A pesquisa qualitativa não direciona seu foco para relevâncias numéricas, mas, sim, a partir de indagações centrais de rupturas do pensamento comum. Os estudos qualitativos, a explanação do objeto, a contextualização, o diálogo de aproximação entre o autor e o tema, inúmeros princípios de estudo, ênfase no ponto de vista do pesquisador, a poética, a coleta de dados com estrutura a definir (ou não), a valorização da experiência e da intuição, são exemplos característicos da pesquisa qualitativa. Esta é também uma pesquisa narrativa, visto que investiga, relaciona, desafia, envolve, distancia-se e aproxima-se com o campo estudado.

Tomando como referência o espaço tridimensional que constitui a pesquisa narrativa, o pesquisador encontra-se sempre num "entremeio", isso porque os participantes da pesquisa, os contextos pesquisados e os próprios pesquisadores constituem-se a partir de dimensões temporais, espaciais, pessoais e sociais. São vidas e histórias em movimento - tanto dos participantes da pesquisa quanto dos pesquisadores, uma vez que a pesquisa narrativa tem como uma de suas características fundantes a relação - que se expressam narrativamente na busca da construção de significados. (CLANDININ, CONNELLY, 2011, p.665)

A pesquisa narrativa propõe, com evidência, textos sobre o campo estudado, podendo ser "histórias de professores, escrita autobiográfica, escrita de diários, notas de campo, fotografias, caixas de memória dentre outros" (CLANDININ, CONNELLY, 2011, p. 665). A partir do projeto "Morro Grande em Arte" 
contemplamos aqui a experiência, os desencontros, o tecer de ideias e todo o percurso do pesquisador e do objeto estudado.

\title{
EXPERIÊNCIA, ARTE E EDUCAÇÃO
}

\begin{abstract}
A experiência ocorre continuamente, porque a interação do ser vivo com as condições ambientais está envolvida no próprio processo de viver. Nas situações de resistência e conflito, os aspectos e elementos do eu e do mundo implicado nessa interação modificam a experiência com emoções e ideias, de modo que emerge a intenção consciente. [...] as coisas são experimentadas, mas não de modo a se comporem em uma experiência singular. [...] quando o material vivenciado faz o percurso até a sua consecução. Então, e só então, ela é integrada e demarcada no fluxo geral da experiência proveniente de outras experiências. (DEWEY, 2010, p. 109-110)
\end{abstract}

Indagação, vivência, inquietação, reflexão, questionamento. Muitas são as palavras utilizadas numa pesquisa sobre arte, mas a minha preferida é experiência. Para Larrosa (2002), "a experiência é o que nos passa, o que nos acontece, ou o que nos toca", ou seja, "a informação não é experiência" (p.21), é aquilo que nos modifica, nos desloca e nos rompe. A experiência para o homem contemporâneo, é cada vez mais infrequente por falta de tempo e de oportunidade, resultando em informações fragmentadas. A experiência nos marca e seu saber se torna "particular, subjetivo, relativo, contingente, pessoal" (p.27), ela transforma e modifica possibilitando ao sujeito da experiência se construir de novo, se reinventar. A experiência na educação tem extrema importância, principalmente no que compete às aulas de Artes. Jacques Rancière (2009a), considera que "as práticas artísticas são "maneiras de fazer" que intervêm na distribuição geral das maneiras de fazer e nas suas relações com maneiras de ser e formas de visibilidade" (p. 17). Em seu livro ${ }^{5}$ "O mestre ignorante: cinco lições sobre a emancipação intelectual", Rancière (2015b) chama de embrutecedor, o educador que adota uma postura de única fonte

${ }^{5}$ RANCIÈRE, Jacques. 0 mestre ignorante: cinco lições sobre a emancipação intelectual. Tradução: Lílian do Valle. 3 ed. Belo Horizonte: Autêntica Editora, 2015. 
de conhecimento, de um patamar tradicionalista, que embrutece $o$ aluno colocandoo na qualidade de expectador passivo. Este que apenas espera que algo aconteça.

A crítica que Ranciére faz ao ensino explicador, a meu ver, se aproxima da ideia de experiência como aquilo que me passa, que tem relação com a paixão e com o espaço que cada sujeito precisa cultivar em si para aprender. O sujeito como uma superfície sensível que é afetada de algum modo por aquilo que acontece,

[...] seja como território de passagem, seja como lugar de chegada ou como espaço do acontecer, o sujeito [...] se define não por sua atividade, mas por sua passividade, por sua receptividade, por sua disponibilidade, por sua abertura. Trata-se, porém, de uma passividade anterior à oposição entre ativo e passivo, de uma passividade feita de paixão, de padecimento, de paciência, de atenção, como uma receptividade primeira, como uma disponibilidade fundamental, como uma abertura essencial (LARROSA, 2004. p. 161).

O sujeito no espaço da emancipação pode e deve ser possibilitado pelos mestres. O espaço da experiência. O mestre embrutecedor e o mestre emancipador, possuem uma grande diferença em outra dicotomia proposta por Rancière (2012c): a passividade e a atividade. "O papel atribuído ao mestre é o de eliminar a distância entre seu saber e a ignorância do ignorante", entendendo que "suas lições e os exercícios que ele dá têm a finalidade de reduzir progressivamente o abismo que os separa" (p. 13). O espectador emancipado, citado pelo autor, é crítico, defende suas colocações e o que acredita, é convicto com suas propostas e está aberto a ampliar seu repertório artístico-cultural. Ele é um estudante ativo, que questiona, propõe relações e dialoga com seus saberes, entendendo-os como fundamentais na sua formação cultural, mas não enquanto dogmas e pressupostos acomodados. Em contraponto, o mestre embrutecedor, corre na contramão desse fluxo, promovendo a passividade intelectual e exigindo aquilo que ele mesmo não consegue promover.

A emancipação, por sua vez, começa quando se questiona a oposição entre olhar e agir, quando se compreende que as evidências que assim estruturam as relações do dizer, do ver e do fazer pertencem à estrutura da dominação e da sujeição. Começa quando se compreende que o olhar é também uma ação que confirma ou transforma essa distribuição das posições. O espectador também age, tal como o aluno ou intelectual. Ele observa, seleciona, compara, interpreta (RANCIÈRE, 2012c, p. 17). 
A experiência dialoga com a estética, a criação e a imaginação. As múltiplas formas de apreciar, olhar, refletir, sentir, relacionar, desconstruir, ressignificar, construir, reconstruir e apropriar, bem como a arte contemporânea propõe, são características da experiência estética. Os espaços de arte, exposições, museus, escolas, apresentações culturais e demais possibilidades, tem uma importância fundamental na experiência estética e na formação de nossos alunos. $O$ professor enquanto partícipe dessas propostas, precisa entender sua função enquanto emancipador dentro do espaço escolar, propondo inúmeras alternativas e caminhos junto com seu aluno, entendendo sua produção e suas questões com potencialidades.

Nossa experiência estética é constituída pelo conjunto de aprendizagens conscientes e sensíveis das quais nos aventuramos a abandonar, mesmo sem querer, para ver o que acontece e então reagir a isso. [...] esse desequilíbrio altera a sensibilidade e nos força a reagir para restabelecê-la, nos força a criar. A experiência estética tem essa característica de desestabilizar provocando-nos sempre a buscar o equilíbrio, e esse movimento, esse acontecimento, pode ser capaz de produzir novas sensibilidades e maneiras de pensar. (HONORATO, 2015, p. 63)

A relação entre escola e curadoria, se dá por necessária, a partir do momento que o educador passa a compreender seu aluno e o espaço de onde ele está inserido, enquanto indivíduos com capacidades múltiplas de saberes. Nessa perspectiva, apresento o termo professor-curador, que se dá a partir de questionamentos e inquietações que tenho enquanto educador ao longo da minha trajetória na educação básica. Segundo Fernando Cocchiarale (2006), o curador tem a função de "criar temas, selecionar os artistas e as obras num circuito de exposições independentes ou institucionais" (p.74). A escola é uma instituição parada num tempo que não é o mesmo dos alunos que fazem parte dela. $O$ professor na condição de curador, se desafia a aproximar essas esferas ${ }^{6}$, ampliando suas estratégias de ensino, convidando esses jovens a encontrarem - juntos - temas pertinentes, evoluindo metodologicamente no contexto em que ambos se inserem e possibilitando espaços que se constituem para além dos muros da escola. A

\footnotetext{
${ }^{6}$ Escola e aluno/Educação e comunidade.
} 
importância da compreensão do aluno, perante as questões e produções compostas por ele próprio, no sentido de impulsionar suas intencionalidades, o torna emancipado. Abrir espaços (físicos ou momentâneos), é ampliar as potencialidades crítico-reflexivas na pesquisa em arte dentro de uma educação emancipatória.

É aí que entra em jogo o imenso poder do imaginário, essa fantástica capacidade de inventar-se continuamente, de criar os meios que nunca existiram, de abrir os caminhos que nunca foram trilhados, de criar uma existência que nunca existiu, de ultrapassar, enfim, as fronteiras da natureza alargando seus horizontes de forma quase infinita. (PINO, 2006, p.49)

O professor-curador, está em uma busca constante por espaços do possíve ${ }^{\Gamma}$ e encara suas aulas com potencialidades de mudar realidades, de ter efeitos transformadores e de valorizar as inquietações de seus alunos. Ele se desafia a pensar as suas práticas, a ser pesquisador e se atualizar constantemente, compreender os interesses dos alunos e costurar estratégias de diálogo entre 0 saber-bagagem do aluno e a ampliação desse contexto. Alves (2010) propõe que "do curador se espera que abra um sentido possível no interior do trabalho de arte, de cada um exibido ou do conjunto deles e, ao mesmo tempo, que dê espaço para que os outros sentidos possam surgir" (p. 46). O professor-curador oportuniza esses jovens em processo de formação, a ampliar suas perspectivas e valorizar as suas particularidades. Ele precisa também dialogar, pesquisar e encontrar meios que façam sentido aos participantes atuantes de suas propostas. Isso não quer dizer, que o professor-curador se reduz a apenas criar exposições com produtos finais. Ele lida com pessoas, onde o processo é muito mais rico e importante: a experiência. Ele não trabalha só, ele caminha com seus alunos e propõe uma construção conjunta de saberes crítico-reflexivos. Dessa forma, ele precisa aproximar as complexidades da arte contemporânea enquanto mecanismos de conhecimento questionador e desconstrutor, se distanciando dos métodos enraizados nas estereotipias.

\footnotetext{
7 Termo utilizado pela autora Aurélia Regina de Souza Honorato (2015), em sua tese intitulada "Trajetórias cartográficas na formação de professores e professoras de artes: espaços do possível", para a obtenção do título de Doutora no Curso de Ciências da Linguagem, promovida pela UNISUL em Tubarão - Santa Catarina. Disponível em: http://pergamum.unisul.br/pergamum/pdf/110516_Aurelia.pdf
} 
Logo, os espaços destinados a reflexão em arte, como museus, exposições e/ou galerias, propõem múltiplas experiências, que são essenciais para a formação do sujeito contemporâneo. Buscar formas de adaptar espaços onde não há valorização destes e nem investimento, é desafiador e complexo. O projeto "Morro Grande em Arte", surge a partir dessa necessidade de encontrar espaços para expor, debater, refletir e contextualizar a arte inquietada pelos alunos da EMEF Prefeito Dário Crepaldi, ampliando seus horizontes e revisitando suas memórias. $O$ processo artístico proposto nas aulas de Artes na escola, sugere vivências críticoreflexivas com o principal intuito de expandir pela cidade de Morro Grande - Santa Catarina, os conceitos debatidos por nós (professor e alunos). "A arte move-se para além dos muros da escola, à espaços que possam proporcionar momentos de apreciação e apropriação estética, onde olhares se cruzam ao mesmo tempo em que se (re) constituem" (FELDHAUS, 2014, p.37).

Esses e outros pressupostos teóricos, são ampliados na sequência a partir dos relatos expostos pelo grupo de alunos, professores e moradores da cidade de Morro Grande, em torno do projeto e suas potencialidades.

\section{MORRO GRANDE EM ARTE: ENTRE RELATOS E EXPERIÊNCIA}

A começar, os relatos são interessantes para que as próximas edições do Morro Grande em Arte sejam cada vez melhores. Ao longo das quatro edições, tentei ao máximo ouvir vários participantes, para compreender as múltiplas visões sobre o evento e também os seus efeitos transformadores. Dessa forma, para a composição dessa pesquisa científica, entrevistei seis pessoas que participaram de todos os quatro anos de projeto, gravando o áudio da conversa e transcrevendo trechos pertinentes ao longo desse trabalho. Nesse grupo estão alunos, professores e comunidade em geral, onde apenas gravei o diálogo sem roteiro pré-estabelecido, cujo desenrolar, se deu a partir do conteúdo das respostas. O objetivo de coletar esses relatos, é de tentar tomar conhecimento das múltiplas experiências e seus efeitos nas quatro edições do projeto, levando em conta visões, idades, críticas e contextos diferentes. Para preservar a identidade de todos os participantes, não 
Criar Educação, Criciúma, v. 8, no2, ago/dez 2019.- PPGE - UNESC - ISSN 2317-2452

mencionarei os nomes dos entrevistados, criando codinomes como participante 1 , participante 2, e assim sucessivamente.

Para iniciar, trago as contribuições da participante 1, que é professora pedagoga e orientadora pedagógica da EMEF Prefeito Dário Crepaldi, tem 44 anos de idade e mais de 20 anos de profissão. Para ela, o projeto Morro Grande em Arte é de suma importância para o desenvolvimento cultural da cidade, valorizando as produções dos alunos e propondo novas possibilidades em torno da Arte. "Se for analisar os anos recentes de emancipação político-administrativa de Morro Grande, nós nunca recebemos ou tivemos o costume de frequentar um evento desse porte. O Morro Grande em Arte nos propõe experiências incríveis e surge para nos possibilitar a frequentar esses espaços e valorizar o que é produzido na região. Os alunos se sentem empolgados enquanto produzem, entendendo que seu trabalho tem potencial para produzir conhecimento, se distanciando do desenho pronto $e$ todos os fantasmas em torno da disciplina de Artes".

Figura 1 - Exposição Morro Grande em Arte - 1ª Edição, 2014.

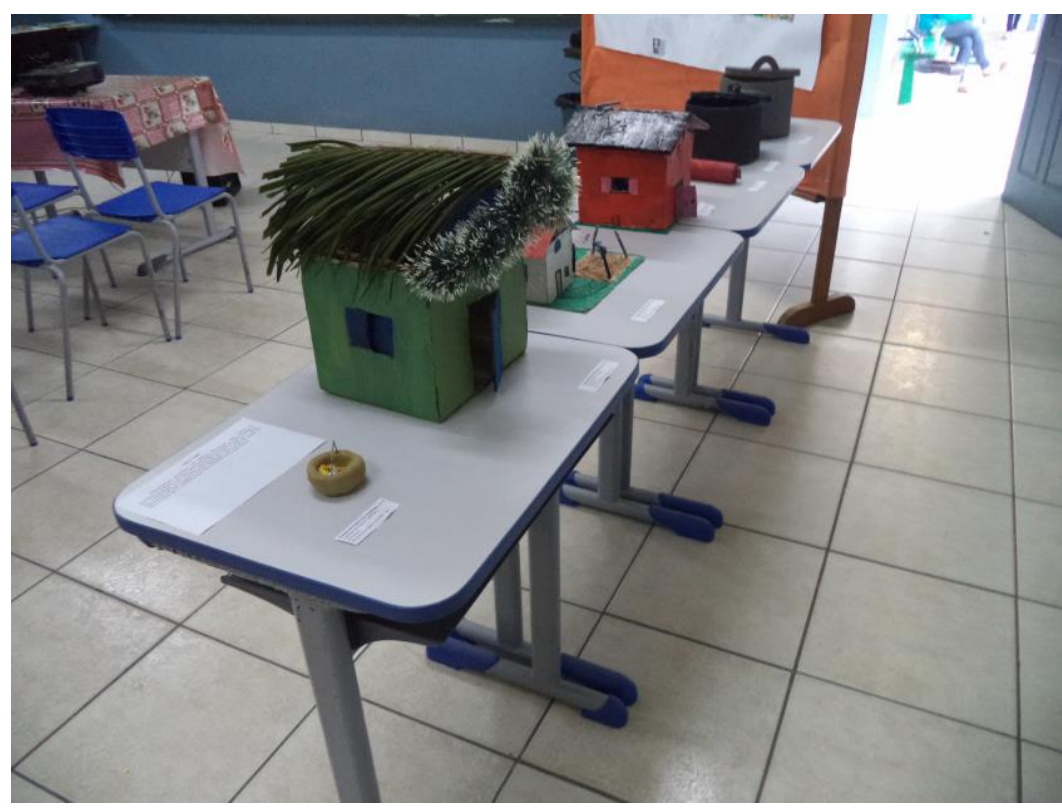

Fonte: Acervo do pesquisador.

Os "fantasmas" colocados pela participante $1 \mathrm{em}$ sua fala, são os estereótipos. Releituras exaustivas enquanto cópias, moldes, fôrmas, 
Criar Educação, Criciúma, v. 8, no2, ago/dez 2019.- PPGE - UNESC - ISSN 2317-2452

lembrancinhas, decoração, sol com olho e boca, boneco de palito, desenhos impressos, metodologias ultrapassadas, distanciamento da realidade do aluno e da cultura local. O projeto Morro Grande em Arte, desde o seu início, propõe uma estrutura desconstrutora, presente nas práticas em sala de aula e na postura em que tentei conduzir o entrelaçar de teoria-prática-conceito-experiência, apostando na arte contemporânea e moderna enquanto caminho para distanciar as estereotipias desse evento.

O estereótipo torna-se alternativa facilmente adotada na expressão plástica por se apresentar como forma segura de representação, um modo de não arriscar, de não se expor. Essa busca de garantia de aprovação resulta em trabalhos mecânicos, acomodados, sem desafios. (BUORO, 2003, p.36)

É nesse contexto que o participante 2, propõe em seus relatos, que sua visão estereotipada de mundo de antes do projeto, foi totalmente influenciada pelo Morro Grande em Arte. Ele enquanto aluno do $9^{\circ}$ ano da EMEF Prefeito Dário Crepaldi, com 15 anos de idade, entendia a arte enquanto propagadora de estereotipias do bonito, da cópia e da idealização do perfeito inalcançável: "Eu sempre imaginei que o artista era um gênio e que nós nunca conseguiríamos ser como ele. Sempre achei que copiar era mais interessante do que eu mesmo criar. Odiava o abstrato e pensava que pintar um desenho estava de bom tamanho. Nunca pensei que a gente poderia pensar ou fazer as pessoas pensarem numa produção de Arte. Depois desse projeto, pude entender que a arte produz sim muito conhecimento, faz as pessoas pensarem. Eu já produzi muita coisa com crítica, com reflexão... coisas com a minha visão de mundo. Fiz parte de todas as edições, do $6^{\circ}$ ao $9^{\circ}$ ano", disse ele. Já a participante 3 , da mesma idade e colega do participante anterior, propõe que se sentiu honrada em poder ter a oportunidade de expor o que produziu, para pessoas fora do ambiente escolar. "Ah... é muito legal poder saber que mais de 600 pessoas passaram a frente do meu trabalho. Dá um certo frio na barriga, mas a gente se sente valorizado. Todo o trabalho que tivemos, a pesquisa que participamos e tudo mais, nos anima em querer expor para as pessoas de fora. Eu acho que nós podemos fazer as pessoas pensarem...mas infelizmente, a sociedade vai para a exposição, esperando encontrar coisas voltadas ao bonitinho, 


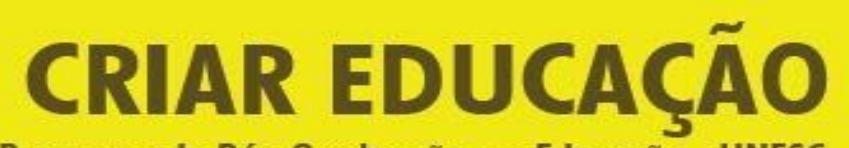

Revista do Programa de Pós-Graduação em Educação - UNESC

Criar Educação, Criciúma, v. 8, no2, ago/dez 2019.- PPGE - UNESC - ISSN 2317-2452

ao artesanato e aos estereótipos. Alguns não compreendem que arte é muito mais que isso. Arte te modifica", disse ela.

Figura 2 - Exposição Morro Grande em Arte - 2ª Edição, 2015.

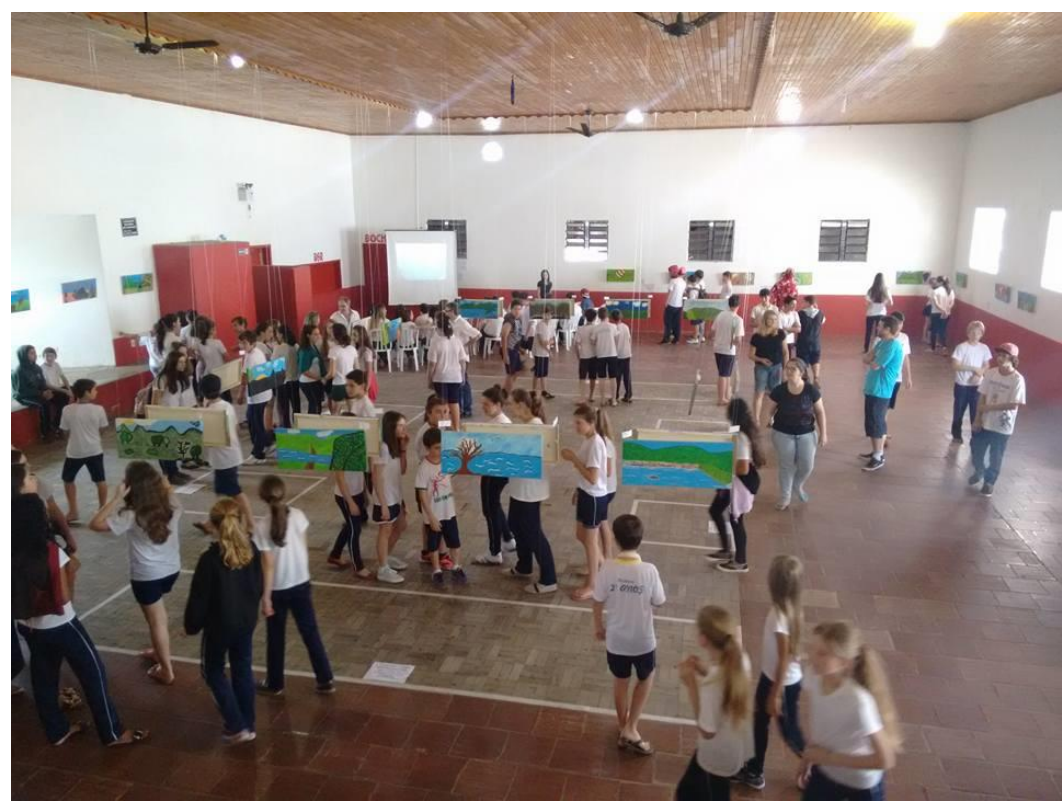

Fonte: Acervo do pesquisador.

O intuito, através dessa lógica, é de tentar com as edições do Morro Grande em Arte, trazer o público para dentro dos espaços e sempre envolver contextos que desconstruam essa visão midiática da arte. A começar pelos alunos e se estender à comunidade em geral, insiro a arte contemporânea, assim como a moderna, no intuito de questionar e inquietar esses pontos levantados pela participante 3. Enquanto professor-curador, tento de várias formas trazer a meu favor, as complexidades em torno da sociedade e da Arte, debatendo e instigando pesquisas, experimentações e reflexões, para construirmos juntos, uma nova edição do projeto que continue a provocar e a mobilizar a comunidade interna e externa da escola a partir do conhecimento e da experiência com a arte.

Realizado o exercício de olhar e contemplar, é preciso partilhar, contribuir para que outras pessoas possam também perceber aquele objeto, descobrir características até então ignoradas, aumentando assim o repertório de todos. Partilhar é descrever, explicitar, situar; é dividir com o outro para multiplicar para todos. Nesse momento, é preciso assegurar a convivência com a diferença sem hierarquizá-la e imprimir-lhe valores, contribuir para a quebra dos estereótipos e para rompimento de preconceitos, fazendo emergir uma maior tolerância com a diversidade. Compartilhar o olhar, 


\section{CRIAR EDUCAÇÃO}

Revista do Programa de Pós-Graduação em Educação - UNESC

Criar Educação, Criciúma, v. 8, no2, ago/dez 2019.-PPGE - UNESC - ISSN 2317-2452

assumido com base nas palavras, é poder assumir-se como sujeito, semelhante e diferente do outro, que traz a diversidade que há em cada ser único como riqueza que precisa estar assegurada em todos os lugares (mesmo dentro da escola). E buscar ir além, trazer informações como possibilidade de ampliação de conhecimentos, expandir a rede de entendimento, possibilitar novas interpretações. (DIAS, 1999, p.180)

Em diálogo com essas inquietações, trago as participantes 4 e 5 que também são colegas dos participantes anteriores, cujas inquietações se entrelaçam na experiência também. Para elas, enquanto integrantes ativas na composição de várias instâncias do projeto, todas experiências em sala de aula antes das respectivas exposições, são tão importantes quanto as do evento expositivo: " $A$ gente aprende muito. Mas é um aprender diferente. A gente vive um monte de coisas legais... pinta, cola, estuda, pesquisa, brinca, enfim, a gente se diverte. Principalmente sendo o último ano nosso na escola, esses momentos ficam marcados na nossa vida. É um orgulho poder fazer parte disso tudo. Dá um trabalho bem grande, mas a gente guarda essas experiências no coração "(Part. 4). "Tudo que a gente viveu no projeto, nos mudou muito. Hoje eu penso diferente sobre muitas coisas. Principalmente quando tive contato com a Arte Moderna e os artistas sendo podados e censurados na época da Primeira e Segunda Guerra Mundial. Esse ano eu produzi textos, desenhos, pintura em tela e mais um monte de coisas. Eu pude expor a minha visão política, social, econômica... minha visão de mundo mesmo. Isso eu constituí ao longo das aulas, das exposições e dos estudos" (Part. $5)$. 


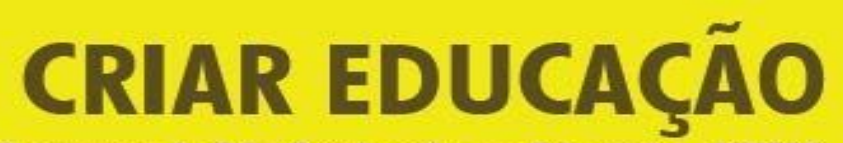

Revista do Programa de Pós-Graduação em Educação - UNESC

Criar Educação, Criciúma, v. 8, no2, ago/dez 2019.-PPGE - UNESC - ISSN 2317-2452

Figura 3 - Exposição Morro Grande em Arte - 3ª Edição, 2016.

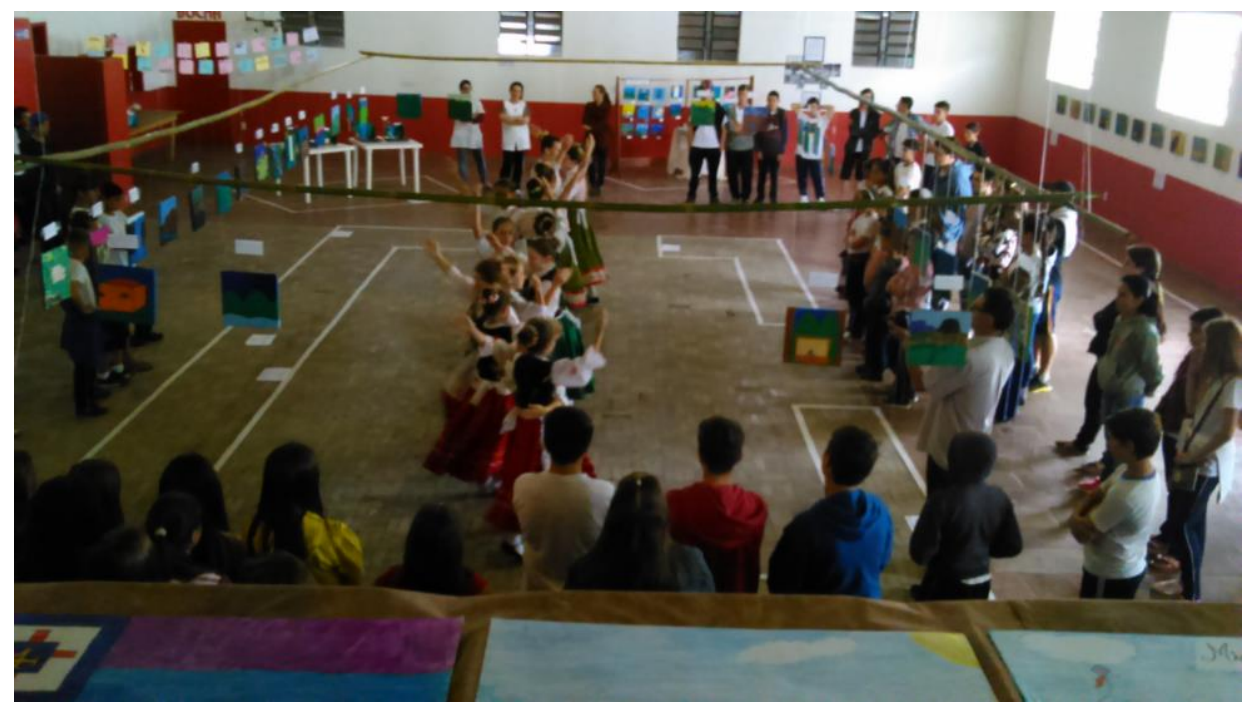

Fonte: Acervo do pesquisador.

Por fim, o participante 6, é de fora do espaço escolar, é aposentado, possui 53 anos de idade e prestigiou todas as quatro edições do projeto. Segundo ele, a exposição cresceu muito ao longo dos anos, onde presenciou produções marcantes e diferenciadas: "Já fui em todas, mas essa edição de 2017, foi a que mais me surpreendeu. Junto com os trabalhos dos alunos, tinha trabalhos de artistas! Nunca imaginei ver de pertinho uma obra de artista. Tinha muita coisa antiga, da época da minha infância também. A qualidade das coisas foi bem interessante. $O$ trabalho dos nossos alunos tem destaque também, a cada ano estão mais legais. Joia! Ano que vem me convida que eu venho de novo". Conforme citado pelo participante, a edição de 2017 contou com produções de artistas convidados, dialogando com objetos históricos das famílias do entorno da escola, além das próprias produções artísticas dos alunos. Foi a maior exposição do evento, em número de trabalhos e de visitantes, sendo inédita na cidade. 
Criar Educação, Criciúma, v. 8, no2, ago/dez 2019.- PPGE - UNESC - ISSN 2317-2452

Figura 4 - Exposição Morro Grande em Arte - 4ª Edição, 2017.

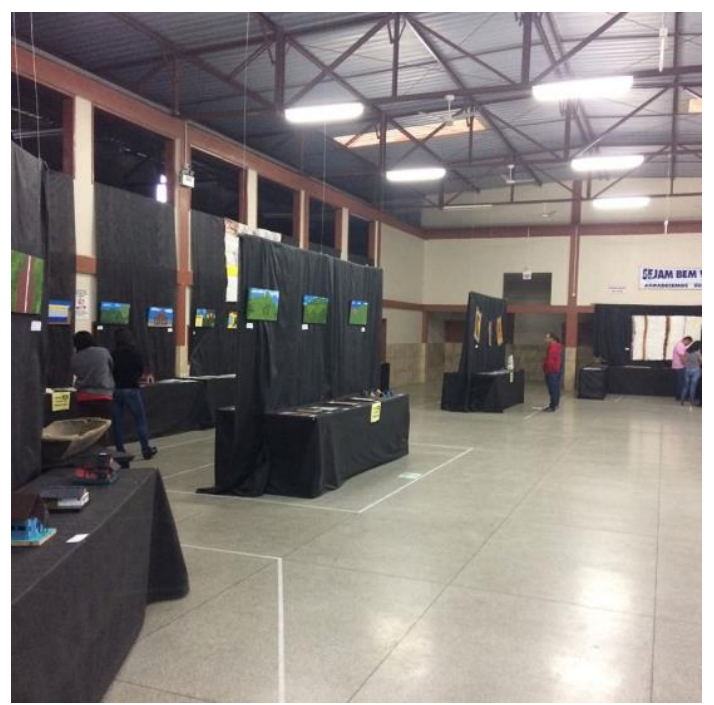

Fonte: Acervo do pesquisador.

A experiência transforma, modifica. A arte tem esse potencial, de nos tocar, nos tirar da zona de conforto, nos propor relações, nos abrir os horizontes, enfim, nos metamorfosear. "De fato, na experiência, o sujeito faz a experiência de algo, mas, sobretudo, faz a experiência de sua própria transformação", dessa forma "[...] a experiência me forma e me transforma" (LARROSA, 2011, p.7). Essa metamorfose que cito, vem das minhas experiências com os meus alunos ao longo desse projeto. Eles me modificaram e me propuseram ser um professor em constante metamorfose, valorizando as suas verdades e entendo-os como produtores de conhecimento.

\section{CONSIDERAÇÕES FINAIS}

Muitos olhos atravessaram as quatro edições do Morro Grande em Arte. Muitos corações, pés, mentes; muitas experiências. Vincent van Gogh, Willy Zumblick, Frida Kahlo, Helio Oiticica, Lygia Clark, Sebastião Salgado, Tarsila do Amaral, Salvador Dalí, Lygia Pape, Munch, Magritte, Duchamp, Bel Duarte, Sergio Honorato, Angelica Neumayer, Malu Dal Pont, e uma grande infinidade de outras grandes referências, foram essenciais para a composição do projeto. Com muito orgulho, esse artigo foi construído em algumas dessas vivências em torno dessa pesquisa de quatro anos. Infelizmente ele não consegue ter uma plataforma que 


\section{CRIAR EDUCAÇÃOO \\ Revista do Programa de Pós-Graduação em Educação - UNESC}

Criar Educação, Criciúma, v. 8, no2, ago/dez 2019.-PPGE - UNESC - ISSN 2317-2452

sustente todas as emoções, as surpresas e os momentos marcantes, mas ele indica que essa ideia está só no seu início. Acredito que experienciar os conteúdos, as técnicas, as reflexões, os conhecimentos, enfim, a arte, é o melhor caminho para a construção de uma educação de qualidade. Crer na capacidade de mudança que os nossos alunos nos propõem, é um dos pilares dessa pesquisa.

Os efeitos transformadores em torno do "Morro Grande em Arte", foram apresentados ao longo da escrita, pelas contribuições dos entrevistados. Surpreendentemente, compreendeu-se a importância das múltiplas vivências em torno do processo até a exposição dos seus respectivos anos. Através disso, trago uma frase que ouvi durante as mediações da quarta edição: "precisamos ter a sensibilidade de olhar e nos oportunizar refletir tudo que tem por aqui”. Infelizmente não sei o nome da pessoa, nem o seu rosto. Mas as suas palavras foram tão tocantes, que a minha experiência naquele espaço, mais uma vez, foi inesquecível. Por entre as vozes e risadas das crianças que por ali estavam, um silêncio me fez refletir essas palavras. Essa sensibilidade do olhar, desde o princípio, sempre foi uma proposta da minha postura enquanto educador. Assim como Rancière e outros autores, o olhar diferente se constitui enquanto experiência em oportunidades como estas. Sendo assim, o oportunizar essas percepções, nos propõe refletir tudo que tem por aqui, tudo que poderá ter e tudo que já teve.

Através disso, com estas e outras contribuições, que desejo que o projeto "Morro Grande em Arte", continue promovendo Espaços do Possível, conforme Honorato (2015) sugere. Seja em centros comunitários, salas de aula ou clubes, o desejo de mudança e de oportunizar experiências, sempre serão prioritários na composição das futuras edições dessa pesquisa. 


\section{CRIAR EDUCAÇÃO}

Revista do Programa de Pós-Graduação em Educação - UNESC

Criar Educação, Criciúma, v. 8, no2, ago/dez 2019.-PPGE - UNESC - ISSN 2317-2452

\section{REFERÊNCIAS}

ALVES, Cauê. A curadoria como historicidade viva. In: RAMOS, Alexandre Dias. Sobre o ofício do curador. Porto Alegre: Zouk, 2010.

BONDÍA, Jorge Larrosa. Notas sobre a experiência e o saber de experiência. Rev. Bras. Educ. [online]. 2002, n.19, pp.20-28. ISSN 1413-2478. http://dx.doi.org/10.1590/S1413-24782002000100003.

CLANDININ, D. Jean; CONNELLY, F. Michael. Pesquisa narrativa: experiência e história em pesquisa qualitativa. Tradução: Grupo de Pesquisa Narrativa e Educação de Professores ILEEI/UFU. Uberlândia: EDUFU, 2011. 250 p.

COCCHIARALE, Fernando. Quem tem medo de arte contemporânea. Recife: Fundação Joaquim Nabuco, Editora Massangana, 2006.

DEWEY, John. Arte como experiencia. Tradução: Vera Ribeiro. São Paulo: Martins Fontes, 2010.

FELDHAUS, Marcelo. Museus, corpo e educação: reflexões a partir da exposição "Museu em Movimento: Rizomas". 2014. 146 f. Dissertação (Mestrado) - Curso de Mestrado em Educação, Universidade do Extremo Sul Catarinense, Criciúma, 2014. Disponível

em: http://repositorio.unesc.net/bitstream/1/3503/1/Marcelo\%20Feldhaus.pdf. Acesso em: 04 de setembro de 2017.

FONSECA, J. J. S. Metodologia da pesquisa científica. Fortaleza: UEC, 2002. Apostila.

GERHARDT, Tatiana Engel; SILVEIRA, Denise Tolfo. Universidade Federal do Rio Grande do Sul (Org.). Métodos de pesquisa. Porto Alegre: UFRGS, 2009. 120 p. (Educação à Distância). Disponível em: http://www.ufrgs.br/cursopgdr/downloadsSerie/derad005.pdf Acesso em: 04 de setembro de 2017. 


\section{CRIAR EDUCAÇÃO}

Revista do Programa de Pós-Graduação em Educação - UNESC

Criar Educação, Criciúma, v. 8, no2, ago/dez 2019.-PPGE - UNESC - ISSN 2317-2452

GIL, Antonio Carlos. Como elaborar projetos de pesquisa. $4^{a}$ ed. São Paulo: Atlas, 2002.

GOLDENBERG, Mirian. A arte de pesquisar: como fazer pesquisa qualitativa em Ciências Sociais. 8 ed. Rio de Janeiro: Record, 2004.

HONORATO, Aurélia Regina de Souza. Trajetórias cartográficas na formação de professores e professoras de Artes: Espaços do possível. 2015. $133 \mathrm{f}$. Tese (Doutorado) - Curso de Doutorado em Ciências da Linguagem, Universidade do Sul de Santa Catarina, Tubarão, 2015.

PINO, Angel. Imaginário e Produção Imaginário: Reflexões em educação. In: DA ROS, Silvia Zanatta; MAHEIRIE, Kátia; ZANELLA, Andréa Vieira (Org). Relações Estéticas, atividade criadora e imaginação: sujeitos e (em) experiência. Florianópolis: NUP/CED/UFSC, 2006, p. 49-75.

RANCIÈRE, Jacques. A partilha do sensível: Estética e Política. $2^{\underline{a}}$ ed. São Paulo: EXO; Editora 34, 2009a.

Jacques. $O$ espectador emancipado. São Paulo: WMF; Martins Fontes, 2012c.

Jacques. 0 mestre ignorante: cinco lições sobre a emancipação intelectual. Tradução: Lílian do Valle. 3 ed. Belo Horizonte: Autêntica Editora, 2015b.

SELTTIZ, Claire. Métodos de pesquisa nas relações sociais. São Paulo: Herder, 1967.

ZAMBONI, Silvio. A Pesquisa em Arte: um paralelo entre arte e ciência. 4. ed. Campinas, SP: Autores Associados, 2012. 